San Jose State University

SJSU ScholarWorks

Faculty Publications, Biological Sciences

Biological Sciences

$1-1-2002$

\title{
Heart rate and energy expenditure of incubating wandering albatrosses: basal levels, natural variation, and the effects of human disturbance
}

$\mathrm{H}$ Weimerskirch

Centre d'Etudes Biologiques de Chizé

Scott A. Shaffer

University of California - Santa Cruz, scott.shaffer@sjsu.edu

G Mabille

Centre d'Etudes Biologiques de Chizé

J Martin

Centre d'Etudes Biologiques de Chizé

O Boutard

Laboratoire de Physiologie des Régulations Energétiques

See next page for additional authors

Follow this and additional works at: https://scholarworks.sjsu.edu/biol_pub

Part of the Biology Commons, and the Marine Biology Commons

\section{Recommended Citation}

H Weimerskirch, Scott A. Shaffer, G Mabille, J Martin, O Boutard, and J-L Rouanet. "Heart rate and energy expenditure of incubating wandering albatrosses: basal levels, natural variation, and the effects of human disturbance" Journal of Experimental Biology (2002): 475-483.

This Article is brought to you for free and open access by the Biological Sciences at SJSU ScholarWorks. It has been accepted for inclusion in Faculty Publications, Biological Sciences by an authorized administrator of SJSU ScholarWorks. For more information, please contact scholarworks@sjsu.edu. 
Authors

H Weimerskirch, Scott A. Shaffer, G Mabille, J Martin, O Boutard, and J-L Rouanet 


\title{
Heart rate and energy expenditure of incubating wandering albatrosses: basal levels, natural variation, and the effects of human disturbance
}

\author{
Henri Weimerskirch ${ }^{1, *}$, Scott A. Shaffer ${ }^{2}$, Geraldine Mabille ${ }^{1}$, Julien Martin ${ }^{1}$, Olivier Boutard ${ }^{3}$ and \\ Jean Louis Rouanet ${ }^{3}$ \\ ${ }^{1}$ Centre d'Etudes Biologiques de Chizé, CNRS, 79360 Villiers en Bois, France, ${ }^{2}$ Department of Ecology and \\ Evolutionary Biology, University of California Santa Cruz, Santa Cruz, CA 95064, USA and ${ }^{3}$ Laboratoire de \\ Physiologie des Régulations Energétiques, Cellulaires et Moléculaires, CNRS, 43 Boulevard 11 Novembre 1918, \\ F-69622, Villeurbanne cedex, France
}

*Author for correspondence: henriw@cebc.cnrs.fr

Accepted 28 November 2001

\begin{abstract}
Summary
We studied the changes in heart rate (HR) associated with metabolic rate of incubating and resting adult wandering albatrosses (Diomedea exulans) on the Crozet Islands. Metabolic rates of resting albatrosses fitted with external HR recorders were measured in a metabolic chamber to calibrate the relationship between HR and oxygen consumption $\left(\dot{V}_{\mathrm{O}_{2}}\right) \quad\left(\dot{V}_{\mathrm{O}_{2}}=\mathbf{0 . 0 7 4} \times \mathbf{H R}+\mathbf{0 . 0 1 9}\right.$, $r^{2}=0.567, P<0.001$, where $\dot{V}_{\mathrm{O}_{2}}$ is in $\mathrm{ml} \mathrm{kg}^{-1} \mathrm{~min}^{-1}$ and $\mathrm{HR}$ is in beats $\mathrm{min}^{-1}$ ). Incubating albatrosses were then fitted with HR recorders to estimate energy expenditure of albatrosses within natural field conditions. We also examined the natural variation in HR and the effects of human disturbance on nesting birds by monitoring the changes in HR. Basal HR was positively related to the mass of the individual. The HR of incubating birds corresponded to a metabolic rate that was 1.5 -fold (males) and 1.8-fold (females) lower than basal metabolic rate (BMR) measured in this and a previous study. The difference was probably attributable to birds being stressed while they were held in the metabolic chamber or wearing a mask. Thus, previous measurements of

metabolic rate under basal conditions or for incubating wandering albatrosses are likely to be overestimates. Combining the relationship between HR and metabolic rate for both sexes, we estimate that wandering albatrosses expend $147 \mathrm{~kJ} \mathrm{~kg}^{-1}$ day $^{-1}$ to incubate their eggs. In addition, the cost of incubation was assumed to vary because (i) HR was higher during the day than at night, and (ii) there was an effect of wind chill $\left(<0^{\circ} \mathrm{C}\right)$ on basal HR. The presence of humans in the vicinity of the nest or after a band control was shown to increase HR for extended periods (2-3h), suggesting that energy expenditure was increased as a result of the disturbance. Lastly, males and females reacted differently to handling in terms of $\mathrm{HR}$ response: males reacted more strongly than females before handling, whereas females took longer to recover after being handled.

Key words: basal metabolic rate, wandering albatross, Diomedea exulans, handling effect, human disturbance, heart rate, oxygen consumption.
\end{abstract}

\section{Introduction}

To measure precisely factors that affect the rate of energy expenditure of free-ranging animals, it is necessary to obtain instantaneous measurements of energy expenditure in the field. Doubly labelled water can be used to estimate energy expenditure but it provides only an average estimate over the measurement period (Speakman, 1997). In contrast, heart rate (HR) provides an instantaneous measurement that can be used to estimate energy expenditure, because $\mathrm{HR}$ and $\dot{\mathrm{V}}_{\mathrm{O}_{2}}$ are directly related, as shown by the Fick equation:

$$
\dot{V}_{\mathrm{O}_{2}}=\mathrm{HR} \times V \mathrm{~S} \times\left(\mathrm{CaO}_{2}-C \mathrm{~V}_{2}\right),
$$

where $\dot{V}_{\mathrm{O}_{2}}$ is oxygen consumption, $V \mathrm{~s}$ is stroke volume of the heart, $\mathrm{CaO}_{2}$ is arterial oxygen concentration, and $\mathrm{Cv}_{\mathrm{O}_{2}}$ is mixed venous blood oxygen concentration (Nolet et al., 1992). Thus,
HR and $\dot{V}_{\mathrm{O}_{2}}$ are correlated if tissue oxygen extraction (i.e. $C \mathrm{aO}_{2}-\mathrm{Cv}_{2}$ ) remains constant or changes systematically with effort (Butler, 1993). Vs also changes with effort, but only in a minor way relative to changes in HR (Butler, 1993). Hence, HR can be used to predict metabolic rate if the relationship is calibrated over a range of HRs. Consequently, numerous studies have examined the relationship between $\mathrm{HR}$ and $\dot{V}_{\mathrm{O}_{2}}$, and results show that the values for each vary linearly in both birds and mammals (Flynn and Gessaman, 1979; Butler et al., 1993; Nolet et al., 1992; Williams et al., 1993; Bevan et al., 1994). Moreover, when coupled with behavioural data, HR can be used to the predict energy expenditure of specific activities (e.g. Bevan et al., 1995; Boyd et al., 1999).

Although open-flow respirometry is the most commonly 
used method used to measure metabolism of resting animals, it is also a method that can impose stress on the animal being measured. For example, animals that are not habituated to the confines of a metabolic chamber, or are subjected to wearing a mask to collect expired gases, may become stressed, thereby producing artificially high measurements. Furthermore, $\dot{V}_{\mathrm{O}_{2}}$ is typically measured for only a few hours in a study period. In contrast, self-contained data loggers can record HR over days or weeks under natural field conditions (Woakes et al., 1995). Thus, the metabolic rates of specific activities such as egg incubation or chick brooding in the field can be estimated by comparing the HR values of birds measured in the metabolic chamber. It is therefore possible to test to what extent resting or basal metabolic rates measured in a metabolic chamber or on birds wearing masks are overestimated as a result of stress.

The incubation period is a critical stage for most birds because adults must continually supply heat to the eggs to maintain optimal temperatures and yet must also provide protection from predators and environmental conditions. Thus in large surface-nesting birds such as albatrosses and large petrels, a breeding pair alternates between incubating the egg and foraging at sea (Lack, 1968; Croxall, 1984). In some instances, incubation bouts may last several weeks (Tickell, 1968). Therefore, a critical element of breeding success is the ability of an individual to fast while on the nest (see Weimerskirch, 1999), because nest abandonment during incubation is a primary cause of breeding failure (Warham, 1990). Fasting capability depends on the quantity of stored body reserves and the rate at which they are consumed. Hence, the rate of energy utilization during incubation can be an important determinant of breeding success in species that experience prolonged incubation bouts.

The energy expenditure of incubating birds might be affected by (i) intrinsic factors, such as the basal metabolic rate and body size, (ii) natural factors, such as meteorological conditions or the presence of predators, and (iii) induced factors, such as the presence of humans and disturbance due to handling. In order to determine which factors (particularly the natural and induced factors) influence energy expenditure, it is important to use a method that can provide instantaneous measures of energy expenditure in the field. HR has proved to be a convenient way to examine this and several studies have measured HR during incubation in free-ranging penguins to focus on the effect of human-induced stress on cardiac response (Culik et al., 1990; Wilson et al., 1991; Nimon et al., 1995). However, no studies have tried to relate the specific behaviour of petrels or albatrosses to HR and energy expenditure during incubation, and only one study has used HR to measure overall energy expenditure during incubation (Bevan et al., 1995). Hence, the effects of disturbance, handling and meteorological conditions on HR and metabolism are unknown for albatrosses and petrels.

The purpose of the present study was fourfold. Firstly, we measured simultaneously HR and $\dot{\mathrm{V}}_{2}$ of resting wandering albatrosses (Diomedea exulans) in a metabolic chamber in order to establish the relationship between them. We then used this relationship to estimate the energy expenditure of incubating albatrosses in the field by measuring the changes in HR over 24-48 hour periods, assuming that the relationship between HR and $\dot{V}_{\mathrm{O}_{2}}$ determined for resting birds in the chamber was similar to that of incubating birds in the field. Secondly, we examined the effects of body mass, age and sex on HRs measured during incubation. Thirdly, we studied the natural variation in HR that was associated with daily rhythms and weather conditions. Lastly, we monitored the variations in HR that were induced by the presence of a human near the nest, and the change in HR caused by handling. Overall, we used the changes in HR to assess the consequences of human disturbance on the energy budgets of incubating albatrosses.

\section{Materials and methods}

The study was conducted during the austral summers January-March 1999 and 2000 on Ile de la Possession, Crozet Islands, southwestern Indian Ocean $\left(46^{\circ} \mathrm{S} 51^{\circ} \mathrm{E}\right)$. Adult wandering albatrosses were studied in the colonies of Baie du Marin and Pointe Basse, where all birds have been monitored regularly since 1966 (for details, see Weimerskirch and Jouventin, 1987). Therefore the breeding status, age and sex of the study birds were known from our long-term database (Weimerskirch and Jouventin, 1987). Two distinct groups of birds were studied. In one group, 41 birds (mixed sexes) were fitted with HR recorders to monitor their heart rate (HR) while sitting on the nest. A total of 33 birds were studied during incubation period and eight during the chick brooding period. All birds were captured on the nest, weighed to the nearest $50 \mathrm{~g}$, fitted with recorders, and then released next to their nest. Total handling time was typically $5-6 \mathrm{~min}$. All birds returned immediately to their nest and continued to incubate the egg or brood the chick. In a second group, eight non-breeding adults were captured while they were visiting the colony of Baie du Marin. Birds were transported in a box to the nearby base $(<0.5 \mathrm{~km})$, weighed with a spring balance, fitted with a HR recorder, and then placed into a box inside the metabolic chamber. After measurements for 3-9h, the equipment was removed and birds were released in the colony.

Non-breeding adults were chosen for the metabolic chamber studies because (i) it was not logistically possible to set up a self-contained (and self-powered) laboratory in the breeding colony; (ii) we chose to avoid the risks of nest desertion by breeding birds because they had to be manipulated and put in a metabolic chamber; and (iii) non-breeding birds are similarly sized to adult birds (Weimerskirch 1992), therefore we would not expect to see physiological differences attributed to maturity or body size.

\section{Heart rate}

The HRs of all study birds were recorded with a HR logger, as used for humans (Polar Electro, Finland) but adapted for use on the albatrosses. The system was composed of two units, a transmitter (Polar PE 4000, 22-40g) and a receiver/logger (Polar Vantage, $32 \mathrm{~g}$ ). The transmission range was about $1 \mathrm{~m}$, 
so the logger was placed in the nest for incubating/brooding birds, or just outside the box but within the metabolic chamber for the laboratory studies. The transmitter was supplied with two 25 -gauge wires $(150 \mathrm{~mm}$ length) to which a gold-plated safety pin electrode was attached at each terminal end. The transmitter was composed of a heart-rate processor that filters electronic signals received by the electrodes to distinguish heartbeats from other electrical activity (e.g. muscle noise). Signals are then amplified and transmitted to the receiver/logger. Similar transmitting modules are integrated in Wildlife Computer (Redmond, WA, USA) HTR logger systems and have been tested and used successfully on marine mammals (Hindell and Lea, 1998). Nevertheless, the reliability and accuracy of the output from these loggers was tested in separate trials on greylag geese (Anser anser). Geese were fitted simultaneously with a Polar logger and electrical leads from a Duograph Racia (Bouscat, France) that recorded electrocardiogram (ECG) signals. The HRs derived from the Duograph were similar to measurements obtained by the Polar loggers. The maximum resolution of the Polar loggers was 240 beats $\mathrm{min}^{-1}$; however, measurements from the Duograph indicated that HRs greater than 240 beats $\mathrm{min}^{-1}$ measured by the Polar units were exactly half of those recorded by the Duograph. Although HRs rarely exceeded 200 beats min $^{-1}$ in resting or incubating wandering albatrosses, we were easily able to derive from the continuous recordings the few values that were higher than 240 beats $\mathrm{min}^{-1}$.

The HR transmitters were attached in the middle of the birds' back with adhesive tape (medical grade) wrapped around several layers of feathers, and electrodes were placed dorsally, under the skin, at a distance of about $250 \mathrm{~mm}$ apart. Prior to insertion of the electrodes, two $1-2 \mathrm{~cm}^{2}$ patches were cleared of all feathers to expose bare skin. Aseptic techniques were used to cleanse the area of electrode insertion and a topical antibiotic ointment was administered to the insertion points upon removal of the electrodes. Given the ease of attachment and quick recovery during attachment and removal of the units, these loggers offer a significant advantage over those that are surgically implanted (Bevan et al., 1994, 1995b) for short- and medium-term deployments.

According to the type of experiment conducted, loggers were programmed to record the average HR over intervals of $5 \mathrm{~s}$ in birds in the metabolic chamber and in the stress experiments, or over $60 \mathrm{~s}$ intervals for longer-term deployments on incubating birds. The lowest average of these HR measurements over a $1 \mathrm{~h}$ period was then considered to be the basal HR of an individual. Incubating or brooding birds wore the HR loggers for periods of $24-36 \mathrm{~h}$.

\section{Energy expenditure}

Energy expenditure was measured by indirect calorimetry using an open-circuit system. After capture, birds were weighed and placed in a 1801 metabolic chamber. The chamber was placed in a thermostatic box (Secasi, Secasi Technologies, Pessac, France) and connected to a vacuum pump, which pulled air through the chamber at a rate of $45-481 \mathrm{~min}^{-1}$. A subsample of the exhaust air from the chamber was drawn continuously through columns of Drierite to trap moisture. Oxygen content was then measured by a Servomex $\mathrm{O}_{2}$ Analyser before the air was finally drawn into an Uros 2 Hartman Braun infrared analyser to measure $\mathrm{CO}_{2}$ content. There was a delay in the system of approximately $50 \mathrm{~s}$ between the time of a breath and a deflection in oxygen and $\mathrm{CO}_{2}$ concentrations measured by the analysers. The fractional oxygen concentration of sampled air was averaged every $20 \mathrm{~s}$ and stored on a computer. Labtech Notebook 5.1.3 software (Labtech, Andover MA, USA) was used to convert changes in fractional oxygen concentration to values of $\dot{\mathrm{O}}_{2}$ in $\mathrm{ml} \mathrm{min}^{-1}$ using the methods of Depocas and Hart (1957). The entire system was calibrated using the $\mathrm{N}_{2}$-dilution method (Fedak et al., 1981) and all gas measurements were corrected to STPD. $\dot{V}_{\mathrm{O}_{2}}\left(\mathrm{ml} \mathrm{min}^{-1}\right)$ was converted to units of energy expenditure assuming $11 \mathrm{O}_{2}$ was equivalent to $20.112 \mathrm{~kJ}$ (Bevan et al., 1995b).

Birds were allowed to settle in the chamber for at least $1 \mathrm{~h}$ before the start of a trial to reach a thermal equilibrium with the chamber air. The temperature inside the chamber was maintained at $8-10^{\circ} \mathrm{C}$, which was equivalent to the outside air temperature. Simultaneous measurements of $\dot{\mathrm{O}}_{2}$ and HR were collected from eight birds during local daylight hours, for periods lasting 3-9h. Steady state measurements of $\dot{V}_{\mathrm{O}_{2}}$ were recorded when gas concentrations within the metabolic chamber had stabilised for at least $30 \mathrm{~min}$. Concomitantly, HRs were averaged over the corresponding periods of stable $\dot{\mathrm{O}}_{2}$ after allowing for the $50 \mathrm{~s}$ time lag. Only recordings exhibiting a steady state for at least $50 \mathrm{~s}$ were used to maximise the range of HR values, to allow us to accurately synchronise HR and $\dot{V}_{\mathrm{O}_{2}}$ measurements. Because stress can affect general circulation patterns, HR and $\dot{V}_{\mathrm{O}_{2}}$, we assumed that oxygen extraction $\left(\mathrm{CaO}_{2}-\mathrm{Cv}_{2}\right)$ and $\mathrm{VS}$ remained constant during all calibration trials. Hence, increases in HR from stress would result from increases in $\dot{\mathrm{O}}_{2}$.

Because all eight birds were adults, measured under ambient conditions (Crozet air temperature during this time period was $9.8 \pm 3.8^{\circ} \mathrm{C}$, mean \pm S.D.), in a resting wakeful state, we considered the lowest measurements of $\dot{\mathrm{O}}_{2}$ averaged over a continuous period of $50 \mathrm{~s}$ to be basal levels. Although a post absorptive state is also a conditional requirement for measurements of basal metabolic rate (BMR), we were unable to confirm the digestive state of the experimental birds. However, our past experience with non-breeding adults suggests that they consume no food while attending the breeding colonies, therefore, their stomachs should have been empty like those of breeding adults returning from sea after a foraging trip during the incubation period $(\mathrm{H}$. Weimerskirch, unpublished observation).

\section{Ambient field conditions and human disturbance experiments}

In 1999, field conditions were monitored with a weather station (Weather Monitor II, Davis Instruments, Hayward CA, USA) that recorded the ambient air temperature and wind direction, speed and wind-chill (calculated to correct for the 
Table 1. Basal values of oxygen consumption $\left(\dot{\mathrm{V}}_{\mathrm{O}_{2}}\right)$ and heart rate $(H R)$ and the intercept (a) and slope (b) of linear regression in wandering albatrosses resting in a metabolic chamber

\begin{tabular}{|c|c|c|c|c|c|c|c|c|c|}
\hline \multirow{2}{*}{$\begin{array}{l}\text { Bird } \\
\text { number }\end{array}$} & \multirow[b]{2}{*}{ Sex } & \multirow{2}{*}{$\begin{array}{l}\text { Mass } \\
(\mathrm{kg})\end{array}$} & \multirow{2}{*}{$\begin{array}{l}\text { Basal } \dot{V}_{\mathrm{O}_{2}} \\
\left(\mathrm{ml} \mathrm{min}^{-1}\right)\end{array}$} & \multirow{2}{*}{$\begin{array}{c}\text { Basal HR } \\
\text { (beats } \text { min }^{-1} \text { ) }\end{array}$} & \multicolumn{5}{|c|}{ Regression equation and statistics } \\
\hline & & & & & $N$ & $a$ & $b$ & $r^{2}$ & $P$ \\
\hline 62 & $\mathrm{~F}$ & 7.75 & 73 & 120 & 34 & 2.909 & 0.054 & 0.577 & $<0.001$ \\
\hline 52 & $\mathrm{~F}$ & 8.70 & 69 & 83 & 19 & -0.007 & 0.094 & 0.840 & $<0.001$ \\
\hline 74 & $\mathrm{~F}$ & 9.10 & 59 & 99 & & & & & \\
\hline 92 & M & 9.70 & 51 & 82 & 37 & 0.790 & 0.067 & 0.354 & $<0.001$ \\
\hline 22 & M & 9.05 & 38 & 89 & 12 & -5.848 & 0.122 & 0.520 & $<0.001$ \\
\hline 42 & M & 10.00 & 42 & 85 & 25 & -0.406 & 0.064 & 0.805 & $<0.001$ \\
\hline All & $\mathrm{F}$ & 8.50 & 67 & 101 & 53 & 4.996 & 0.042 & 0.436 & $<0.001$ \\
\hline All & M & 9.60 & 44 & 85 & 104 & 1.315 & 0.055 & 0.354 & $<0.001$ \\
\hline $\mathrm{O}_{2}$, oxygen con & ption & & & & & & & & \\
\hline
\end{tabular}

effect of wind speed on temperature) (ADT, 1999) at the study colony of Pointe Basse where incubating birds were fitted with HR recorders.

In order to assess the effects of human disturbance on nesting wandering albatrosses, we used the changes in HR as a proxy for induced stress. In these trials, birds were selected from a sub-colony at Pointe Basse that do not normally encounter human interaction except for brief band controls once or twice a breeding season. Hence, these birds were unaccustomed to a regular human presence in the colony. Furthermore, the density of nests in this sub-colony is very low compared to the other study colonies, therefore, these birds experience little interaction with conspecifics.

Three types of manipulations were conducted. Firstly, we measured the time required for HR to return to basal levels after birds were fitted with the HR loggers. Secondly, we measured the changes in HR associated with the presence of a human at measured distances from the bird on its nest. This involved observing a bird from a distance out of view with a chronometer that was synchronized with the HR logger worn by the study bird. Then, a second observer approached the bird at timed intervals following a straight-line trajectory towards the nest. The hidden observer noted the behaviour of the bird, and the time and distances between the nest and the second observer. The time at which the bird first detected the second observer's presence, as well as the distance to the nest, were noted. The second observer continued to approach the bird to a distance of $1 \mathrm{~m}$, and then moved away from the nest until no longer visible by the bird. A third manipulation was conducted like the second, except that upon final approach, the bird was captured by its beak and the metal identification band around its tarsus was read. This band control lasted approximately $10-20 \mathrm{~s}$.

Each bird served as its own control. Thus, after being equipped with HR loggers, birds were not visited again for another $6-12 \mathrm{~h}$ in order to collect baseline data. Furthermore, these birds were only visited during an experimental trial; therefore, during the majority of the measurement period, birds experienced natural conditions with possible interactions with conspecifics or predators like skuas. All three manipulations were conducted on each study bird, and given the low frequency and short duration of each encounter, we examined whether birds would exhibit the same intensity of change in HR between experimental manipulations.

\section{Analysis}

The data were analysed using SYSTAT 8.0 (Wilkinson, 1998). When several measurements for the same bird were obtained, data were averaged to avoid problems with pseudoreplication. Unless otherwise stated, values presented in the text and in the table are means \pm 1 S.D.

\section{Results}

\section{Relationship between energy expenditure and heart rate}

Of the eight study birds placed in the metabolic chamber, BMR was obtained for only three males and three females (Table 1) because the steady state condition was not reached in the other two birds. $\dot{V}_{\mathrm{O}_{2}}$ was significantly higher for females than for males, in both absolute and mass-specific terms (Mann-Whitney test, $U=9.0, P=0.05$ ). The average BMR was $7.95 \pm 1.48 \mathrm{ml} \mathrm{O}_{2} \mathrm{~kg}^{-1} \mathrm{~min}^{-1}$ (or $230 \mathrm{~kJ} \mathrm{~kg}^{-1} \mathrm{day}^{-1}$ ) for females and $4.75 \pm 0.53 \mathrm{ml} \mathrm{O}_{2} \mathrm{~kg}^{-1} \mathrm{~min}^{-1}$ (or $138 \mathrm{~kJ} \mathrm{~kg}^{-1} \mathrm{day}^{-1}$ ) for males, or $6.35 \pm 2.05 \mathrm{ml} \mathrm{O}_{2} \mathrm{~kg}^{-1} \mathrm{~min}^{-1}$ (or $184 \mathrm{~kJ} \mathrm{~kg}^{-1} \mathrm{day}^{-1}$ ) for both sexes combined. In contrast to BMR, basal HRs of birds in the metabolic chamber were not significantly different between males and females (Table 1, Mann-Whitney test, $U=7.0, P=0.275$ ).

The relationship between $\dot{V}_{\mathrm{O}_{2}}$ and HR was obtained for five out of eight individuals. In all cases, $\dot{\mathrm{O}}_{2}$ was significantly correlated with HR (Table 1, Fig. 1) and the slopes of the individual linear regressions were not significantly different (ANCOVA, $F_{4,117}=1.1, P=0.131$ ); however, the intercepts were $\left(F_{4,121}=39.9, P<0.001\right)$. In this situation, it is statistically acceptable to use the slope from the pooled data and the mean intercept to predict $\dot{V}_{\mathrm{O}_{2}}$ from HR (Bevan et al., 1994). Thus, the equation for all the data pooled is $\dot{V}_{\mathrm{O}_{2}}=0.074 \times \mathrm{HR}+0.019$ $\left(r^{2}=0.567, P<0.001\right)$, where $\dot{V}_{\mathrm{O}_{2}}$ is in $\mathrm{ml} \mathrm{kg}^{-1} \mathrm{~min}^{-1}$ and HR is 


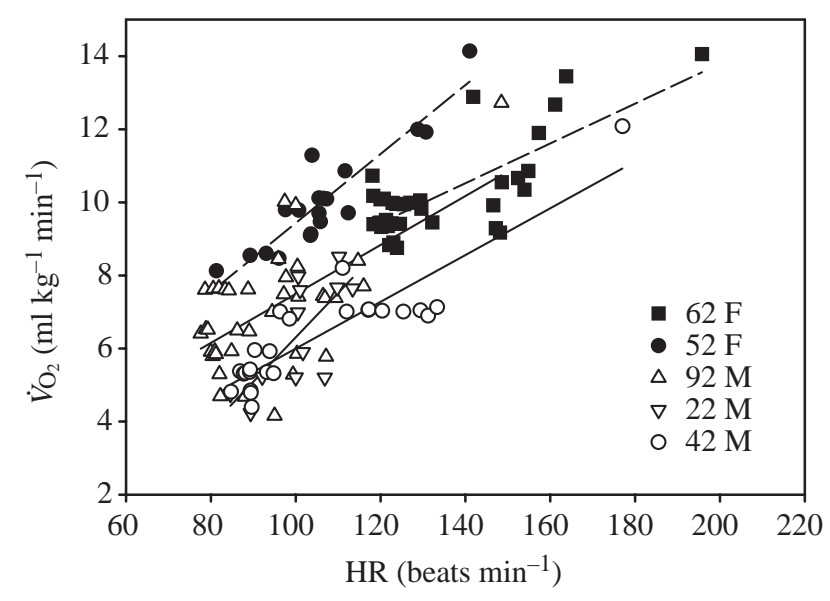

Fig. 1. The functional relationship between heart rate (HR) and oxygen consumption $\left(\dot{V}_{\mathrm{O}_{2}}\right)$ of five wandering albatrosses resting in a metabolic chamber. Black symbols represent data for two females and white symbols represent data for three males. Similarly, dashed regression lines indicate relationships for females and solid lines indicate relationships for males. For regression equations, see Table 1.

in beats $\mathrm{min}^{-1}$. When considering the sexes separately, again there was no significant difference in the slopes (ANCOVA; $\left.F_{1,123}=1.4, \quad P=0.238\right)$ but the intercepts were highly significantly different $\left(F_{1,124}=74.2, P<0.001\right)$.

\section{Basal and average heart rate levels}

Fig. 2 shows an example of a recording of HR over a period of $32 \mathrm{~h}$ from an incubating female wandering albatross. Excluding the first $3 \mathrm{~h}$ that correspond to the recovery after initial handling, there were peaks in HR that occurred at various intervals throughout the record (Fig. 2). Overall, the basal HR of incubating birds averaged $56.9 \pm 11.4$ beats min $^{-1}$ $\left(N=33\right.$, range $40.0-83.5$ beats $\left.\mathrm{min}^{-1}\right)$, which corresponded to an energy expenditure of $85.4 \mathrm{~J} \mathrm{~kg}^{-1} \mathrm{~min}^{-1}$. Basal HRs were similar for males and females $\left(F_{1,32}=0.959, \quad P=0.334\right)$. Furthermore, basal HRs were significantly related to the mass of each individual (Fig. 3). The basal HR of all incubating birds was significantly lower than the basal HR of birds in the metabolic chamber $(93.0 \pm 14.6 ; t=6.92$, d.f. $=38, P<0.001)$.
The daily average HR (measured over 24h) for an incubating bird was $68.1 \pm 12.0$ beats $\mathrm{min}^{-1}$ (range 48.7-93.5 beats $\mathrm{min}^{-1}$ ), which was not significantly different between the sexes $\left(F_{1,22}=0.184, P=0.672\right)$. This HR would be equivalent an energy expenditure of $147 \mathrm{~kJ} \mathrm{~kg}^{-1}$ day ${ }^{-1}$. The ratio between daily average and basal HR was $1.21 \pm 0.06$ and the two variables were highly significantly correlated $(r=0.95$, $N=24, P<<0.001)$. In addition, the residuals of the regression between basal and average HR were positively correlated to the mass of the individuals $(r=0.550, N=19, P=0.015)$, indicating that heavier individuals had higher average HRs than the value predicted by their basal HR. Lastly, there was no influence of age of the individuals on basal or average HR, nor on the residuals of the regression between basal and average HR $(P>0.1)$.

\section{Brooding period}

During the brooding period, the HRs of adults showed regular peaks of longer durations compared to the peaks in HR observed during incubation. The basal HR was $57.0 \pm 14.0$ beats $\min ^{-1}(N=8)$, which was similar to the basal HR of incubating birds ( $t=0.01$, d.f. $=40, P=0.997$ ). However, the daily average HR during the brooding period was $72.6 \pm 17.7$ beats min $^{-1}$ and the ratio between basal and daily average HR was $1.33 \pm 0.08$, which was significantly higher than that for the incubation period ( $t=3.88$, d.f. $=28, P=0.001)$. The daily average HR for brooding birds would be equivalent to an energy expenditure of $157 \mathrm{~kJ} \mathrm{~kg}^{-1} \mathrm{day}^{-1}$.

\section{Natural variation of heart rates during incubation}

Because basal HRs varied extensively between individuals $(\mathrm{CV}=20.3 \%)$, we used relative values to study the influence of various natural factors on HR. For each individual, values were expressed as a percentage of basal values. Relative HRs varied significantly throughout the day $\left(F_{23,351}=1.72, \quad P=0.022\right.$; Fig. 4). The differences between periods of the day were mainly attributed to the high mean HR values between 08:00 and 13:00 local time (Fig. 4).

There was no effect of air temperature, precipitation or wind speed on relative HR. However, when considering wind-chill for temperatures below $0^{\circ} \mathrm{C}$, relative $\mathrm{HR}$ significantly
Fig. 2. Changes in heart rate (HR) over an incubation bout $(32 \mathrm{~h})$ of a female wandering albatross. The decrease during the first $3 \mathrm{~h}$ corresponds to the recovery period after handling, which was necessary in order to attach the HR logger onto the bird. Black boxes indicate periods of night time.

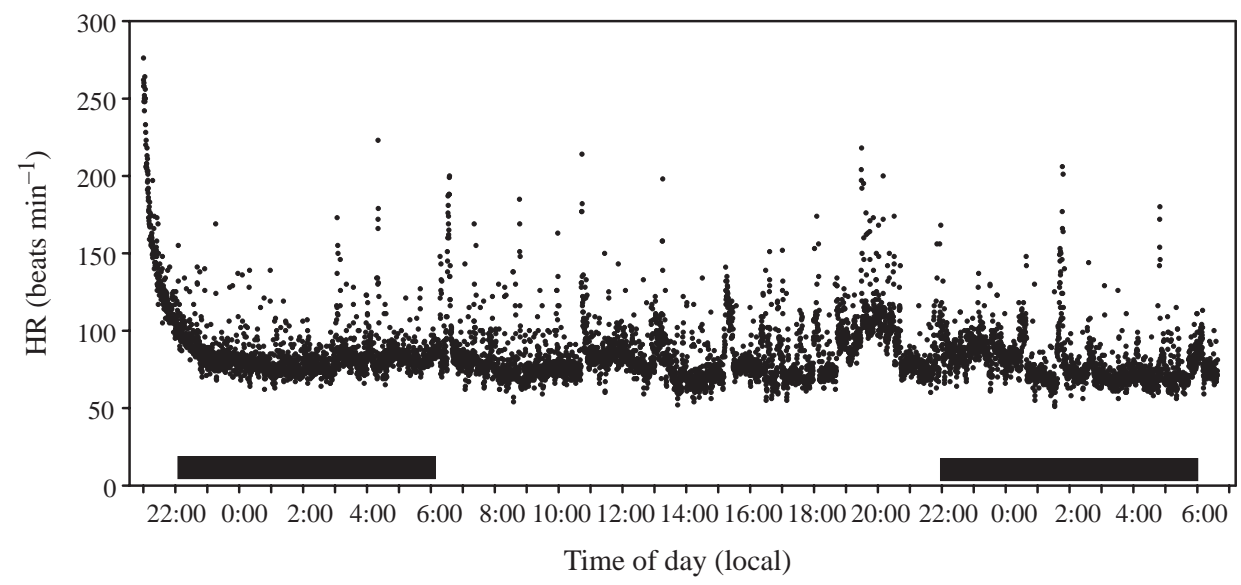




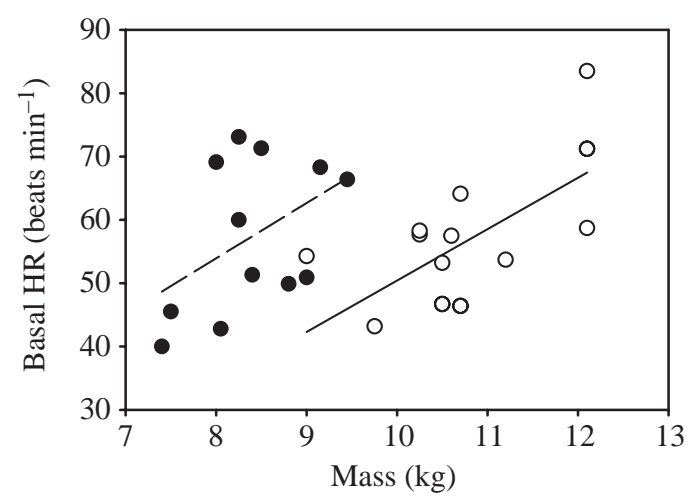

Fig. 3. The relationship between basal heart rate (HR) and body mass of male and female wandering albatrosses (white symbols are males, $y=8.122 x-30.8, r^{2}=0.441, P=0.007$; and black symbols are females, $\left.y=8.75 x-16.1, r^{2}=0.236, P=0.090\right)$.

increased as wind-chill decreased ( $r=0.634, N=44, P<0.001$; Fig. 5). Conversely, there was no effect of wind-chill on relative $\mathrm{HR}$ for temperatures above $0{ }^{\circ} \mathrm{C}(r=0.017, N=323$, $P=0.762$ ).

\section{Changes in heart rates induced by human disturbance}

Human presence in the vicinity of the incubating bird appeared to induce an increase in HR as soon as the bird detected the observer. This result was the same for males and females (Fig. 6). The mean HR of incubating birds continued to increase as the observer approached with males exhibiting a higher relative HR average compared to females when the observer was within $50 \mathrm{~m}$ from the nest (Fig. 6). However, when birds were captured by the beak for a band control, HR of both sexes peaked at similar values (Fig. 6). Interestingly, the mean recovery HR values immediately following a band control showed significant sex differences. The HR decreased fairly rapidly within the first 3-7 min after release, but the recovery for males was more rapid than for females (Fig. 6). Basal HR was subsequently attained within $9 \mathrm{~min}$ for males and $12 \mathrm{~min}$ for females (Fig. 6).

When birds were released after being fitted with HR recorders, HR values were 4.3-fold higher than the basal HR (366 $\pm 116 \%$ of basal rate). This value was significantly lower than when birds were handled for a band control $(434 \pm 89 \%$ of basal rate, $t=2.15, N=14, P=0.037$ ). On average, $120 \mathrm{~min}$ was required for HR to return to basal levels (Fig. 2). Initially, males appeared to recover faster (Fig. 7), but this difference was only significant within $20-30 \mathrm{~min}$ of release. Beyond that, there were no significant sex differences for recovery to basal levels $\left(F_{1,31}=1.65, P=0.208\right)$.

For eight individuals a second band control was carried out $5-18 \mathrm{~h}$ later to examine whether birds would react as strongly (i.e. show a similar change in HR) to a second band control. In all of the second trials, there was no difference in relative HR between the two sessions when (i) the visitor was first detected (paired $t$-test, $t=-1.08, P=0.329$ ), (ii) when the visitor was at less $20 \mathrm{~m}$ from the nest (paired $t$-test, $t=-0.341$, $P=0.738$ ) or (iii) when the bird was captured for band control (paired $t$-test, $t=0.278, P=0.807$ ).

\section{Discussion}

\section{Evaluation of BMR and the cost of incubation}

The combined mean minimum energy expenditure of wandering albatrosses resting in the metabolic chamber $(184 \mathrm{~kJ}$ $\mathrm{kg}^{-1} \mathrm{day}^{-1}$ ) was lower than the results obtained by Brown and Adams (1984) (216 $\left.\mathrm{kJ} \mathrm{kg}^{-1} \mathrm{day}^{-1}\right)$ for the same species under similar conditions. Both of these estimates for BMR are lower than values obtained for incubating wandering albatrosses measured with respirometry techniques. Brown and Adams (1984) measured $\dot{V}_{\mathrm{O}_{2}}$ of five female wandering albatrosses that were incubating an egg and determined that the cost of incubation was approximately 1.4-fold higher than their measured BMR ( $\left.305 \mathrm{~kJ} \mathrm{~kg}^{-1} \mathrm{day}^{-1}\right)$. Using our revised estimate of BMR, the cost of incubation would be 1.7-fold greater. However, we believe that the previous estimates of incubation cost, and both BMR measurements, are overestimated because the basal HRs of incubating birds in the present study were 1.5fold (males) to 1.8-fold (females) lower than HRs of birds resting in the metabolic chamber. These HRs correspond to a basal energy expenditure of $123 \mathrm{~kJ} \mathrm{~kg}^{-1} \mathrm{day}^{-1}$ for incubating wandering albatrosses, which is a value nearly 2.5 -fold lower than the previous cost of incubation estimated by Brown and Adams (1984).

Even though the HR of incubating birds varied throughout the day (Fig. 2), and also with the presence of humans and handling (Figs 6, 7), HRs returned to near basal levels within 2-3h, unlike the birds resting in the metabolic chamber, where relatively high HRs were maintained. This suggests that birds resting in the metabolic chamber were stressed, resulting in artificially high BMR measurements. Moreover, considering that birds in the

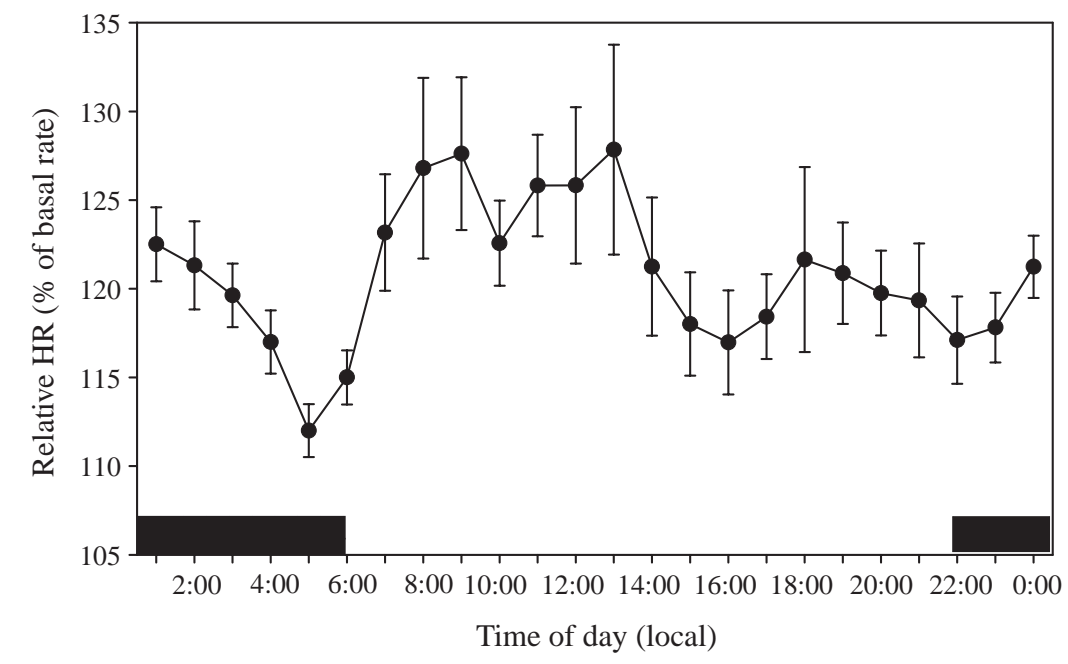

Fig. 4. Changes in relative heart rates (HR) throughout the day of incubating wandering albatrosses. Values are means \pm 1 S.D. Black boxes indicate periods of night-time. 


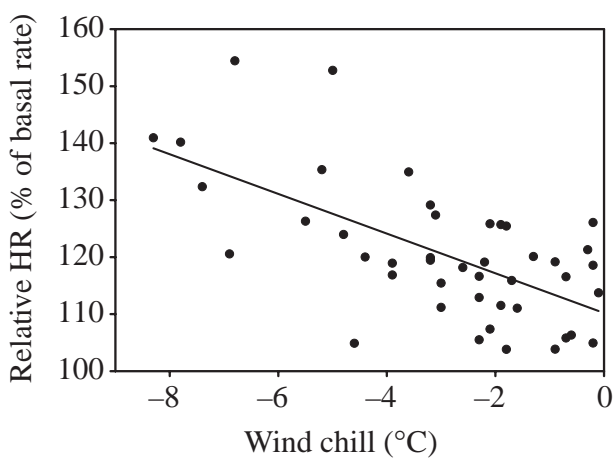

Fig. 5. The change in relative heart rate (HR) as a function of windchill $\left(<0{ }^{\circ} \mathrm{C}\right)$ in incubating wandering albatrosses.

chamber were stressed, we believe that birds equipped with a mask, such as those studied by Brown and Adams (1984) to measure the cost of incubation, would also be stressed. It was even suggested that their birds fitted with a mask over the bill appeared agitated, especially males, which would lead to artificially high estimates of energy expenditure for incubating wandering albatrosses, and mean that they were not able to measure the cost of incubation for male wandering albatrosses.

Using the average HR of an incubating bird measured over a $24 \mathrm{~h}$ period, we estimate that the daily cost of incubation for wandering albatrosses is $147 \mathrm{~kJ} \mathrm{~kg}^{-1} \mathrm{day}^{-1}$. This revised estimate is derived from the relationship between HR and $\dot{V}_{\mathrm{O}_{2}}$, assuming the relationship remains linear over the range of HRs measured during incubation. In a separate study that used doubly labelled water, Shaffer et al. (2001) determined the field metabolic rate of incubating wandering albatrosses to be $169 \mathrm{~kJ} \mathrm{~kg}^{-1}$ day $^{-1}$, which was close and not statistically different from our estimate using HR. Thus, two separate methods provided similar results, suggesting that incubation costs for wandering albatrosses are substantially lower than the previous estimates determined by Brown and Adams (1984) and Croxall and Ricketts (1983). In the study by Croxall and Ricketts, the cost of incubation was estimated by measuring the rate of loss of body mass of incubating wandering albatrosses. It is well known that estimates of metabolism based on loss of body mass are subject to error because of the assumptions that have to be made about the metabolites oxidised for energy yield from mass loss (Groscolas and Clement, 1976; Brown and Adams, 1984; Groscolas et al., 1991).

Our results show that HR can be used to derive a significantly lower estimate of incubation cost compared to previous studies. However, the results were dependent on the calibration between HR and $\dot{\mathrm{V}}_{2}$ from birds that were resting in a metabolic chamber. Thus, it is important to consider the potential source of error that this may have caused in our estimates of metabolic cost for incubating birds. The slopes of the regressions between HR and $\dot{V}_{\mathrm{O}_{2}}$ for all five individuals that were measured in the chamber were not significantly different from each other despite variations in body mass and sex (see Results, Table 1). There was, however, considerable variation (CV approx. 700\%) between the intercepts of the regressions for each bird. Thus, in the absence of data on incubating birds in the field, we have to assume that the greatest potential source of error in our estimate using the equation for the relationship between HR (beats $\mathrm{min}^{-1}$ ) and $\dot{V}_{\mathrm{O}_{2}}\left(\mathrm{ml} \mathrm{kg}^{-1} \mathrm{~min}^{-1}\right)$ for all birds combined, would be the assumption of a common intercept. Therefore, we modelled the sensitivity of a change in predicted $\dot{V}_{\mathrm{O}_{2}}$ by modifying the intercept of the equation $\left(\dot{V}_{\mathrm{O}_{2}}=0.074 \times \mathrm{HR}+0.019\right)$ while keeping the slope constant. Because the intercept of the equation essentially goes through the origin (and is therefore very small), a large change in the intercept (as large as $\pm 1000 \%$ ) only has a minor impact on predicted $\dot{V}_{\mathrm{O}_{2}}( \pm 3.3 \%$ of original value). Consequently, the equation we derived from our calibration appears to be robust enough to account for some variation between individuals, giving us confidence in the predicted metabolic rate of incubating birds in the field. Furthermore, our estimate of daily energy expenditure of an incubating bird (see above) was similar to estimates determined by a different technique in another study (Shaffer et al., 2001).

\section{Factors affecting basal and average heart rates and energy expenditure}

The relationship between HR and $\dot{V}_{\mathrm{O}_{2}}$ was highly significant (Table 1) and the regression for both sexes combined passed through the origin. Nonetheless, when males and females were analysed separately, the intercepts for each equation differed but the slopes were similar. The difference between intercepts of each regression could reflect intrinsic differences between the sexes (e.g. body size). Alternatively, the difference could be attributed to the fact that females responded differently in

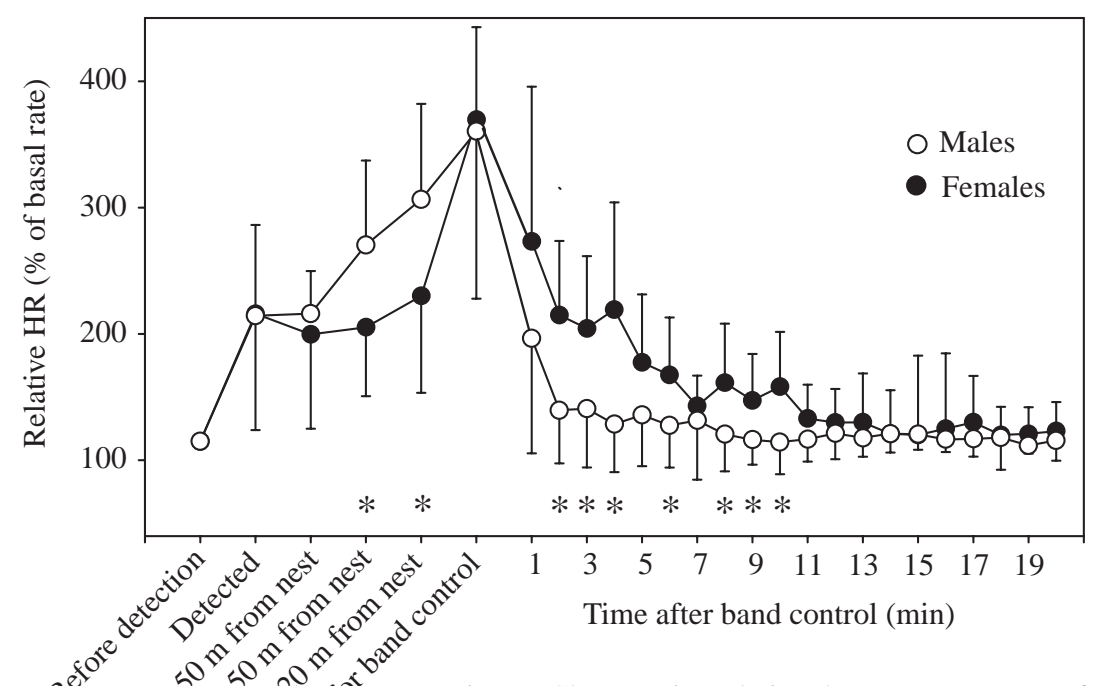

Fig. 6. Changes in relative heart rates (HR) of male and female wandering albatrosses before, during, and after a band control. Asterisks indicate statistically significant differences between the two sexes $(t$-test, $P<0.05)$. 


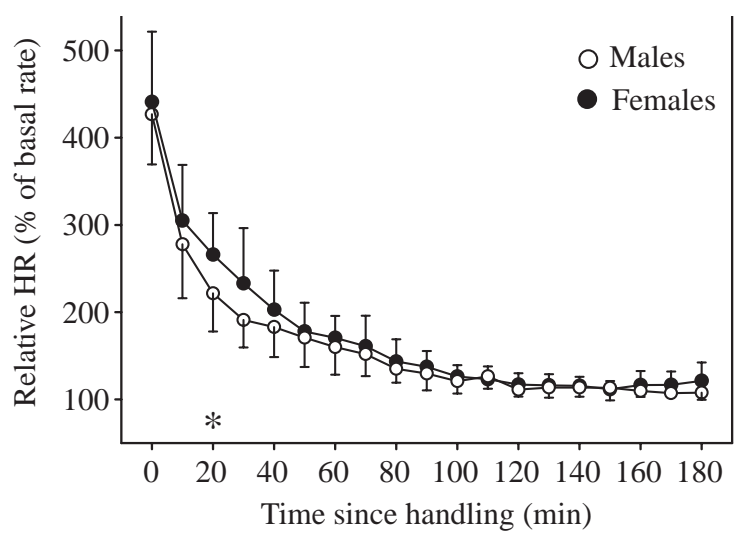

Fig. 7. Changes in relative heart rate (HR) of male and female wandering albatrosses after being equipped with HR loggers. The asterisk indicates a statistically significant difference between the two sexes $(t$-test, $P<0.05)$.

the metabolic chamber. The resting HR and $\dot{\mathrm{O}}_{2}$ of females in the chamber was higher than those of males, suggesting that females were more stressed. Furthermore, females exhibited a similar trend in the field because they had higher HRs and longer recovery times following a band control or handling.

The basal HRs obtained during incubation reflect a low BMR for wandering albatrosses. In addition, basal values were not significantly different between males and females. However, basal HR positively correlated with the mass of the individual (Fig. 3). Similarly, Bech et al. (1999) showed that the BMR of kittiwakes increased with the body mass of individuals; hence, intraspecific mass seems to be an important factor affecting basal values of HR, and probably BMR. Basal HR also correlated with average HR of incubating birds because we found a significant relationship between the mass of an individual and the residuals of the regression between basal and average HR, emphasizing the importance of the mass of individuals in determining HR and therefore the energy expenditure of incubating birds.

\section{Natural factors affecting heart rate}

When undisturbed by a human presence, incubating wandering albatrosses exhibited important variations in HR (e.g. Fig. 2). For example, field observations collected out of view from the incubating bird revealed that some changes in HR were associated with interactions with conspecifics, potential predators like skuas, or with activities such as wing beating, standing or preening. All these activities increased HR by approximately $20 \%$ over basal levels. In addition, when parents were brooding their chick, energy expenditure was slightly higher, which was probably attributed to the greater frequency of postural changes associated with chick provisioning. The cost of heating the chick may also be greater than cost of heating the egg. Bevan et al. (1995) also observed slight increases in energy expenditure in brooding compared to incubating black-browed albatrosses.

In addition to the occurrence of short-term changes in HR, there were significant daily variations in average HR (Fig. 4). At night, and especially during the second part of the night, average HR decreased to near basal levels (i.e. within 10\%). This decrease in HR was probably related to the absence of interactions with conspecifics or predators. The reduction in activity and/or alertness probably allows birds to sleep uninterrupted for longer periods, thus accounting for the decrease in HR. Conversely, average HR increased to the average maximum during the initial morning hours. It is unclear why this occurs because activity in the colony is typically constant throughout the day for breeding birds (Weimerskirch and Lys, 2000), as opposed to peaks in activity for non-breeding birds in the early evening. Interestingly, the existence of diurnal variation in HR of wandering albatrosses contrasts with the absence of such variations in incubating Adélie penguins (Culik et al., 1989).

The HRs of incubating albatrosses did not exhibit a relationship with air temperature. However, incubating birds responded to decreasing wind-chill temperatures (combination of wind speed and temperature) by increasing HR (Fig. 5). This effect may be attributed to a disruption of the plumage by the wind, which could reduce the bird's thermal insulation. Given that HR increased over basal levels when wind chill was below $0{ }^{\circ} \mathrm{C}$, we might expect the lower critical temperature of wandering albatrosses breeding on Crozet to occur at or around $0{ }^{\circ} \mathrm{C}$. Crozet wandering albatrosses live in a mild climate compared to colder breeding sites such as South Georgia, where temperatures are often negative during the summer when birds are incubating eggs. Such differences probably result in higher costs of incubation at the colder sites.

\section{Effects of human disturbance on heart rate and energy expenditure}

The results of the present study show that incubating wandering albatrosses exhibit a distinct physiological response when approached or handled. It was clear that HRs nearly doubled upon first detection of a human presence, and that further increases in HR of three- to fourfold over basal levels occurred when birds were handled (Fig. 6). If the relationship between HR and $\dot{\mathrm{V}}_{2}$ scales linearly under conditions of stress, then the increase in HR before handling and the prolonged recovery period after handling could raise the energy expenditure of an incubating bird. Such an increase in energy expenditure is not negligible, especially if birds are handled multiple times and/or for prolonged periods. However, given that wandering albatrosses are large relative to most other sea birds, they have a wider margin of safety in the form of body reserves that could buffer them from the impact of increased energy expenditure caused by periodic stress. For smaller species, the stress of human disturbance could have a greater impact, because the safety margin of energy stores decreases with body size (Weimerskirch, 1999).

It is interesting to note that males and females responded differently to the presence of humans. Males appeared to increase their HR more rapidly than females, when approached by humans. In contrast, females required more time to recover to basal levels after a band control. Males 
could be more prone to stress, and therefore react more aggressively than females towards a threat. This would be consistent with the sex difference in HR responses exhibited when birds were disturbed. Interestingly, penguins appear to react more vigorously to the presence of humans than albatrosses (Culik et al., 1989; Wilson et al., 1991), yet both are surface-nesting species that rely on a single parent to incubate the egg and defend the nest. Nevertheless, the results of the present study and those conducted on penguins indicate that the degree of stress is variable according to sex and species considered.

In conclusion, the changes in HR associated with specific behaviour have proved to be a very useful metric by which to estimate energy expenditure of birds in natural conditions and to gauge the effect of disturbance that birds may be subjected to. Being able to estimate energy expenditure of incubating birds using HRs also allowed us to demonstrate that estimates of energy expenditure using a metabolic chamber or a mask on wild birds probably overestimate metabolic rate. The differences in energy expenditure that we observed were substantial, thus caution is warranted when comparison of BMR are made between species.

This study was supported by Institut Français pour la Recherche et la Technologie Polaire (IFRTP, Programme no. 109, and Programme no. 131, directed by C. Duchamp). We thank Daniel Costa, Terrie Williams and Catherine Mac Sweeney for helpful comments and technical advice on the manuscript, and Tatiana Guionnet, Anne Hoecker and Yann Tremblay for assistance in the field.

\section{References}

ADT (1999). Calculating Windchill values. National Center for Atmospheric Research, http://www.atd.ucar.edu/homes/rilling/wc_formula.html.

Bech, C., Langseth, I. and Gabrielsen, G. W. (1999). Repeatability of basal metabolism in breeding female kittiwakes Rissa trydactyla. Proc. R. Soc. Lond. B 266, 2161-2167.

Bevan, R. M., Woakes, A. J. and Butler, P. J. (1994). The use of heart rate to estimate oxygen consumption of free-ranging black-browed albatrosses Diomedea melanophrys. J. Exp. Biol. 193, 119-137.

Bevan, R. M., Butler, P. J., Woakes, A. J. and Prince, P. A. (1995). The energy expenditure of free-ranging black-browed albatrosses. Phil. Trans. R. Soc. Lond. B 350, 119-131.

Boyd, I. L., Bevan, R. M., Woakes, A. J. and Butler, P. J. (1999). Heart rate and behavior of fur seals: implications for measurement of field energetics. Am. J. Physiol. 276, H844-H857.

Brown, C. R. and Adams, N. J. (1984). Basal metabolic rate and energy expenditure during incubation in the wandering albatross (Diomedea exulans). Condor 86, 182-186.

Butler, P. J. (1993). To what extent can heart rate be used as an indicator of metabolic rate in free-living marine mammals? In Marine Mammals: Advances in Behavioural and Population Biology, vol. 66 (ed. I. L. Boyd), pp. 317-332. Oxford: Clarendon Press.

Butler, P. J., Woakes, A. J. and Bishop, C. M. (1998). Behaviour and physiology of Svalbard Barnacle Geese Branta leucopsis during their autumn migration. J. Avian Biol. 29, 536-545.

Croxall, J. P. and Ricketts, C. (1983). Energy costs of incubation in the wandering albatross Diomedea exulans. Ibis 125, 33-39.
Croxall, J. P. (1984). Seabird ecology. In Antarctic Ecology (ed. R. M. Laws). New York: Academic Press.

Culik, B. M., Adelung, D., Heise, M., Wilson, R. P., Coria, N. R. and Spairani, H. J. (1989). In situ heart rate and activity of incubating Adélie penguins (Pygoscelis adeliae). Polar Biol. 9, 365-370.

Culik, B. M., Adelung, D. and Woakes A. J. (1990). The effect of disturbance on the heart rate and behaviour of Adélie penguins (Pygoscelis adeliae) during the breeding season. In Antarctic Ecosystems Ecological Changes and Conservation (ed. K. R. Kerry and G. Hempel), pp. 177-182. Heidelberg: Springer-Verlag.

Depocas, F. and Hart, J. S. (1957). Use of Pauling oxygen analyser for measurement of oxygen consumption of animals in open-circuit systems and in short-lag, closed circuit apparatus. J. Appl. Physiol. 10, 388-392.

Fedak, M. A, Pullen, M. R. and Kanwisher, J. (1981). One-step N2-dilution technique for calibrating open-circuit $\dot{V}_{\mathrm{O}_{2}}$ measuring systems. J. Appl. Physiol. 51, 772-776.

Flynn, R. K. and Gessaman, J. A. (1979). An evaluation of heart rate as a measure of daily metabolism in pigeons (Columbia livia). Comp. Biochem. Physiol. 63A, 511-514.

Groscolas, R. and Clement, C. (1976). Utilisation des réserves énergétiques au cours du jeûne de la reproduction chez le manchot empereur Aptenodytes forsteri. CR Acad. Sci. Ser. D 282, 297-300.

Groscolas, R., Schreiber, L. and Morin, F. (1991). The use of tritiated water to determine protein and lipid utilization in fasting birds: a validation study in incubating great-winged petrels, Pterodroma macroptera. Physiol. Zool. 64, 1217-1233.

Hindell, M. A. and Lea, M. A. (1998). Heart rate, swimming speed and estimated oxygen consumption of free-ranging southern elephant seals. Physiol. Zool. 71, 74-84.

Lack, D. (1968). Ecological Adaptations for Breeding in Birds. London: Methuen.

Nimon, A., Schroter, R. C. and Stonehouse, B. (1995). Heart rate of disturbed penguins. Nature 374, 415.

Nolet, B. A., Butler, P. J., Masman, D. and Woakes, A. J. (1992). Estimation of daily energy expenditure from heart rate and doubly labelled water in exercising geese. Physiol. Zool. 65, 1188-1216.

Shaffer, S. A., Costa, D. P. and Weimerskirch, H. (2001). Comparison of methods to evaluate energy expenditure of incubating wandering albatrosses. Physiol. Biochem. Zool. 74, 823-831.

Speakman, J. R. (1997). Doubly Labelled Water: Theory and Practice. London: Chapman \& Hall.

Tickell, W. L. N. (1968). The biology of the great albatrosses Diomedea exulans and D. epomophora. Ant. Res. Ser. 12, 1-55.

Warham, J. (1990). The Petrels: Their Ecology and Breeding Systems. San Diego, CA: Academic Press.

Weimerskirch, H. (1992). Reproductive effort in long-lived birds: agespecific patterns of condition, reproduction and survival in the wandering albatross. Oïkos 64, 464-473.

Weimerskirch, H. (1999). The role of body condition in breeding and foraging decisions in albatrosses and petrels. In Proc. 22 Int. Ornithol. Congr. Durban (ed. N. J. Adams and R. H. Slotow), pp. 1178-1189. BirdLife South Africa, Johannesburg.

Weimerskirch, H. and Jouventin, P. (1987). Population dynamics of the wandering albatross of the Crozet islands: consequences of the population decline. Oikos 49, 315-322.

Weimerskirch, H. and Lys, P. (2000). Seasonal changes in the provisioning behaviour and mass of male and female wandering albatrosses in relation to the growth of their chick. Polar Biol. 23, 733-744.

Wilkinson, L. (1998). SYSTAT 8. 0: Statistics. SPSS Inc., Chicago, Illinois.

Williams, T. M., Friedl, W. A. and Haun, J. E. (1993). The physiology of bottlenose dolphins (Tursiops truncatus): heart rate, metabolic rate and plasma lactate concentration during exercise. J. Exp. Biol. 179, 31-46.

Wilson, R. P., Culik, B., Dannfeld, R. and Adelung, D. (1991). People in Antarctica: how much do Adélie penguins (Pygoscelis adeliae) care? Polar Biol. 11, 363-370.

Woakes, A. J., Butler, P. J. and Bevan, R. M. (1995). An implantable data logger system for heart rate and body temperature: its application to the estimation of field metabolic rates in Antarctic predators. Med. Biol. Engng. Comput. 33, 145-152. 